\title{
Potential impact of a nonavalent HPV vaccine on the occurrence of HPV-related diseases in France
}

\author{
Didier Riethmuller ${ }^{1}$, Anne-Carole Jacquard ${ }^{2}$, Jean Lacau St Guily ${ }^{3}$, François Aubin ${ }^{4}$, Xavier Carcopino ${ }^{5}$, Pierre Pradat ${ }^{6}$, \\ André Dahlab² and Jean-Luc Prétet ${ }^{7,8,9}$
}

\begin{abstract}
Background: Human Papillomavirus (HPV) infection is known to be associated with a number of conditions including cervical, vaginal, vulvar, penile, anal neoplasias and cancers, oropharynx cancers and genitals warts (GW). Two prophylactic vaccines are currently available: a bivalent vaccine designed to prevent HPV type 16 and 18 infection and a quadrivalent vaccine targeting HPV 6, 11, 16, and 18. In France, HPV vaccination is recommended in 11-14 year-old girls with a catch-up for girls aged 15-19. The objective of this study was to assess the potential impact of an HPV 6/11/16/18/31/33/45/52/58 nonavalent vaccine on anogenital and oropharyngeal HPV-related diseases in France.
\end{abstract}

Methods: HPV genotype distributions from 6 multicentric retrospective studies (EDiTH I to VI) were analyzed including 516 cases of invasive cervical cancers (ICC), 493 high-grade cervical neoplasias (CIN2/3), 397 low-grade squamous intraepithelial lesions (LSIL), 423 GW, 366 anal cancer and 314 oropharyngeal carcinomas. Low and high estimates of HPV vaccine impact were calculated as follows: low estimate: prevalence of HPV 6/11/16/18/31/33/45/52/58 genotypes alone or in association but excluding presence of another HPV type; high estimate: prevalence of HPV 6/11/16/18/31/ 33/45/52/58 genotypes alone or in association, possibly in presence of another HPV type.

Results: Estimates of potential impact varied from 85\% (low estimate) to 92\% (high estimate) for ICC, 77\% to 90\% for CIN2/3, 26\% to 56\% for LSIL, $69 \%$ to $90 \%$ for GW, $81 \%$ to $93 \%$ for anal cancer, and $41 \%$ to $44 \%$ for oropharyngeal carcinomas. Compared to the quadrivalent vaccine, the proportion of additional cases potentially prevented by the nonavalent vaccine was 9.9\%-15.3\% for ICC, 24.7\%-33.3\% for CIN2/3, 12.3\%-22.7\% for LSIL, 2.1\%-5.4\% for GW, 8.5\%-10.4\% for anal cancer, and 0.0\%-1.6\% for oropharyngeal carcinoma.

Conclusions: The nonavalent HPV vaccine showed significant increased potential impact compared to the HPV 6/11/16/18 quadrivalent vaccine for ICC, CIN2/3 and LSIL. Considering a 100\% vaccine efficacy and high vaccine coverage, about $90 \%$ of ICC, CIN2/3, GW or anal cancer cases could be prevented by a nonavalent HPV vaccine in France.

Keywords: HPV, Human papillomavirus, Vaccine, Invasive cervical cancer, Cervical intraepithelial neoplasia, Genital warts, Anal cancer

\section{Background}

Human Papillomavirus (HPV) infection is known to be associated with a number of conditions including cervical, vaginal, vulvar, penile, anal neoplasias and cancers, oropharynx cancers and genitals warts (GW) [1-5]. Two prophylactic vaccines using L1 virus-like particles (VLP) are available and widely marketed internationally. These vaccines were primarily developed with the aim of reducing

\footnotetext{
* Correspondence: acjacquard@spmsd.com

${ }^{2}$ Sanofi Pasteur MSD, 12 rue Jonas Salk, 69367 Lyon, Cedex 07, France

Full list of author information is available at the end of the article
}

HPV-related cervical cancer. The first one $\left(\right.$ Cervarix $\left.^{\circ}\right)$ is a bivalent vaccine designed to prevent high-risk HPV type 16 and 18 infection. The second one (Gardasil $\left.{ }^{\circ}\right)$, is a quadrivalent vaccine targeting HPV 6, 11, 16, and 18 [6], HPV lowrisk types 6 and 11 being associated with $90 \%$ of GW $[7,8]$. In France, HPV vaccination is recommended in 11-14 yearold girls with a catch-up for girls aged 15-19 [9].

Worldwide studies in invasive cervical cancer (ICC) cases reported that the most commonly encountered HPV types after HPV 16 and 18 were HPV 31, 33, 35, 45, 52, and $58[10,11]$. Merck has been developing a nonavalent 
vaccine targeting five additional high-risk HPV types (HPV 31/33/45/52/58) to the HPV types 6/11/16/18 contained in the quadrivalent vaccine [12]. Serrano et al. estimated that the addition of HPV 31/33/45/52/58 to HPV types included in current vaccines could prevent almost $90 \%$ of ICC cases worldwide [13].

The French EDiTH studies (Etude de la Distribution des Types d'HPV) reported the HPV genotype distribution in invasive cervical cancer (EDiTH I) [14], high-grade cervical neoplasias (CIN2/3) (EDiTH II) [15], low-grade squamous intraepithelial lesions (LSIL) (EDiTH III) [16], external acuminata condylomata (genital warts) (EDiTH IV) [17], anal cancer (EDiTH V) [18] and oropharyngeal cancer (EDiTH VI) [19]. In these studies, the estimated potential impact of a 6/11/16/18 quadrivalent vaccine varied from $14-33 \%$ in LSIL to about $70-83 \%$ in cervical or anal cancers.

These studies have shown that a proportion of HPVrelated lesions were not targeted by currently available vaccines. The objective of the present study was thus to assess the potential impact in France of a 6/11/16/18/31/ $33 / 45 / 52 / 58$ nonavalent HPV vaccine on anogenital and oropharyngeal HPV-related diseases, and to compare this impact with the 6/11/16/18 quadrivalent vaccine.

\section{Methods}

\section{Studies}

We reanalyzed data from 6 multicenter retrospective studies (EDiTH I to EDiTH VI) published elsewhere [14-19]. For each study, details regarding patients' data, histological specimens' inclusion/exclusion criteria, DNA isolation, HPV genotyping and ethical considerations can be found in the respective publications.

\section{Statistical analysis}

Histological specimens of 516 invasive cervical cancers (HPV prevalence, 97.1\%), 493 high grade cervical neoplasias (HPV prevalence, 98.2\%), 397 low-grade squamous intraepithelial lesions (HPV prevalence, 98.2\%), 423 external acuminata condylomata (HPV prevalence, 98.8\%), 366 anal cancer (HPV prevalence, 96.7\%) and 314 oropharyngeal carcinomas (HPV prevalence, 46.5\%) were included in the analysis.

For each condition, HPV genotype distributions were used to assess the potential impact of the quadrivalent and the nonavalent vaccines in France. A low and a high estimate of the vaccine impact were calculated as follows. For the quadrivalent vaccine, low estimate was the prevalence of HPV 6/11/16/18 genotypes alone or in association but excluding presence of another HPV type; high estimate was the prevalence of HPV 6/11/16/18 genotypes alone or in association possibly in presence of another HPV type. For the nonavalent vaccine, low estimate was the prevalence of HPV 6/11/16/18/31/33/45/
52/58 genotypes alone or in association but excluding presence of another HPV type; high estimate was the prevalence of HPV 6/11/16/18/31/33/45/52/58 genotypes alone or in association possibly in presence of another HPV type. Additional file 1: Table S1 presents genotypes and combination of genotypes used to define the low and high estimates for the quadrivalent and nonavalent vaccines. Estimates are presented with their 95\% confidence intervals calculated based on the cumulative binomial distribution.

The absolute additional potential impact of the nonavalent vaccine, i.e. the proportion of additional cases potentially prevented by the nonavalent vaccine compared to the quadrivalent vaccine, was calculated as follows:

$$
\frac{n_{\text {nonavalent }}-n_{\text {quadrivalent }}}{N} \times 100
$$

with $n$ being the number of cancer cases potentially prevented and $N$ the total number of cancer cases.

The relative additional potential impact of the nonavalent vaccine compared to the quadrivalent vaccine was calculated as follows:

$$
\frac{n_{\text {nonavalent }}-n_{\text {quadrivalent }}}{n_{\text {quadrivalent }}} \times 100
$$

with $n$ representing the number of potentially prevented cancer cases.

\section{Results}

HPV genotypes in the six EDiTH studies are described in details in Table 1 . Single infections by HPV 6/11/16/ $18 / 31 / 33 / 45 / 52 / 58$ were found in $362(70.2 \%), 299$ (60.6\%), 84 (21.2\%), 251 (59.3\%), 257 (70.2\%) and 130 (41.4\%) of invasive cervical cancers, high-grade cervical neoplasias, low-grade squamous intraepithelial lesions, external acuminata condylomata, anal cancer and oropharyngeal carcinomas, respectively. Corresponding multiple infections by HPV 6/11/16/18/31/33/45/52/58, excluding any other HPV genotype, were found in $74(14.3 \%), 79$ (16.0\%), 19 (4.8\%), 39 (9.2\%), 39 (10.7\%) and $0(0,0 \%)$, and corresponding multiple infections by HPV 6/11/16/18/31/ $33 / 45 / 52 / 58$, with or without another HPV genotype, in 113 (21,9\%), 142 (28,8\%), 139 (35,0\%), 131 (31,0\%), 84 $(23,0 \%)$ and $8(2,5 \%)$.

The potential impact of the quadrivalent and nonavalent HPV vaccines assessed by low and high estimates is presented in Figure 1. The nonavalent HPV vaccine showed increased impact compared to the quadrivalent vaccine for invasive cervical cancers, high-grade cervical neoplasias and low-grade squamous intraepithelial lesions. The number of genotypes targeted by the nonavalent vaccine varied between $84.5 \%$ (low estimate, 95\% CI 81.0 to 87.8 ) and $92.1 \%$ (high estimate, $95 \% \mathrm{CI}$ 89.5 to 94.3 ) for invasive cervical cancers, between 
Table 1 HPV genotype distribution in the different EDiTH studies

\begin{tabular}{|c|c|c|c|c|c|c|}
\hline & $\begin{array}{l}\text { Invasive cervical } \\
\text { cancers } \\
\mathrm{n}\end{array}$ & $\begin{array}{l}\text { High-grade cervical } \\
\text { neoplasias } \\
\text { n }\end{array}$ & $\begin{array}{l}\text { Low-grade squamous } \\
\text { intraepithelial lesions } \\
n\end{array}$ & $\begin{array}{l}\text { External acuminata } \\
\text { condylomata } \\
\mathrm{n}\end{array}$ & $\mathrm{n}$ & $\begin{array}{l}\text { Oropharyngeal } \\
\text { carcinomas } \\
\mathrm{n}\end{array}$ \\
\hline $\mathrm{HPV}(+)$ & $501(97.1)$ & $484(98.2)$ & $390(98.2)$ & $418(98.8)$ & $354(96.7)$ & $146(46.5)$ \\
\hline HPV (-) & $15(2.9)$ & $9(1.8)$ & $7(1.8)$ & $5(1.2)$ & $12(3.3)$ & $168(53.5)$ \\
\hline Total & $516(100)$ & $493(100)$ & $397(100)$ & $423(100)$ & $366(100)$ & $314(100)$ \\
\hline Total single infections & $386(74.8)$ & $333(67.5)$ & $192(48.4)$ & $281(66.4)$ & $265(72.4)$ & $138(43.9)$ \\
\hline Total single infections $6 / 11 / 16 / 18$ & $316(61.2)$ & $203(41.2)$ & $50(12.6)$ & $248(58.6)$ & $234(63.9)$ & $130(41.4)$ \\
\hline Single infections 6 & $1(0.2)$ & $0(0.0)$ & $11(2.8)$ & $195(46.1)$ & $13(3.6)$ & $0(0.0)$ \\
\hline Single infections 11 & $1(0.2)$ & $1(0.2)$ & $0(0.0)$ & $42(9.9)$ & $4(1.1)$ & $0(0.0)$ \\
\hline Single infections 16 & $275(53.3)$ & $199(40.4)$ & $31(7.8)$ & $11(2.6)$ & $216(59.0)$ & $130(41.4)$ \\
\hline Single infections 18 & $39(7.6)$ & $3(0.6)$ & $8(2.0)$ & $0(0.0)$ & $1(0.3)$ & $0(0.0)$ \\
\hline Total single infections 31/33/45/52/58 & $46(8.9)$ & $96(19.5)$ & $34(8.6)$ & $3(0.7)$ & $23(6.3)$ & $0(0.0)$ \\
\hline Single infections 31 & $17(3.3)$ & $41(8.3)$ & $8(2.0)$ & $1(0.2)$ & $4(1.1)$ & $0(0.0)$ \\
\hline Single infections 33 & $11(2.1)$ & $27(5.5)$ & $1(0.3)$ & $0(0.0)$ & $11(3.0)$ & $0(0.0)$ \\
\hline Single infections 45 & $9(1.7)$ & $0(0.0)$ & $6(1.5)$ & $0(0.0)$ & $0(0.0)$ & $0(0.0)$ \\
\hline Single infections 52 & $6(1.2)$ & $13(2.6)$ & $8(2.0)$ & $1(0.2)$ & $5(1.4)$ & $0(0.0)$ \\
\hline Single infections 58 & $3(0.6)$ & $15(3.0)$ & $11(2.8)$ & $1(0.2)$ & $3(0.8)$ & $0(0.0)$ \\
\hline Total single infections 6/11/16/18/31/33/45/52/58 & $362(70.2)$ & $299(60.6)$ & $84(21.2)$ & $251(59.3)$ & $257(70.2)$ & $130(41.4)$ \\
\hline Single infections others & $24(4.7)$ & $34(6.9)$ & $108(27.2)$ & $30(7.1)$ & $8(2.2)$ & $8(2.5)$ \\
\hline Total multiple infections & $115(22.3)$ & $151(30.6)$ & $198(49.9)$ & $137(32.4)$ & $89(24.3)$ & $8(2.5)$ \\
\hline $\begin{array}{l}\text { Multiple infections 6/11/16/18 excluding any other } \\
\text { HPV genotypes }\end{array}$ & $41(7.9)$ & $11(2.2)$ & $4(1.0)$ & $19(4.5)$ & $24(6.6)$ & $0(0.0)$ \\
\hline $\begin{array}{l}\text { Multiple infections } 6 / 11 / 16 / 18 \text { with or without } \\
\text { another HPV genotype }\end{array}$ & $108(20.9)$ & $116(23.5)$ & $83(20.9)$ & $125(29.6)$ & $76(20.8)$ & $3(1.0)$ \\
\hline $\begin{array}{l}\text { Multiple infections } 6 / 11 / 16 / 18 / 31 / 33 / 45 / 52 / 58 \\
\text { excluding any other HPV genotypes }\end{array}$ & $74(14.3)$ & $79(16.0)$ & $19(4.8)$ & $39(9.2)$ & $39(10.7)$ & $0(0.0)$ \\
\hline $\begin{array}{l}\text { Multiple infections 6/11/16/18/31/33/45/52/58 with } \\
\text { or without another HPV genotype }\end{array}$ & $113(21.9)$ & $142(28.8)$ & $139(35.0)$ & $131(31.0)$ & $84(23.0)$ & $8(2.5)$ \\
\hline $\begin{array}{l}\text { Multiple infections other HPV excluding } \\
6 / 11 / 16 / 18 / 31 / 33 / 45 / 52 / 58\end{array}$ & $2(0.4)$ & $9(1.8)$ & $59(14.9)$ & $6(1.4)$ & $5(1.4)$ & $0(0.0)$ \\
\hline
\end{tabular}




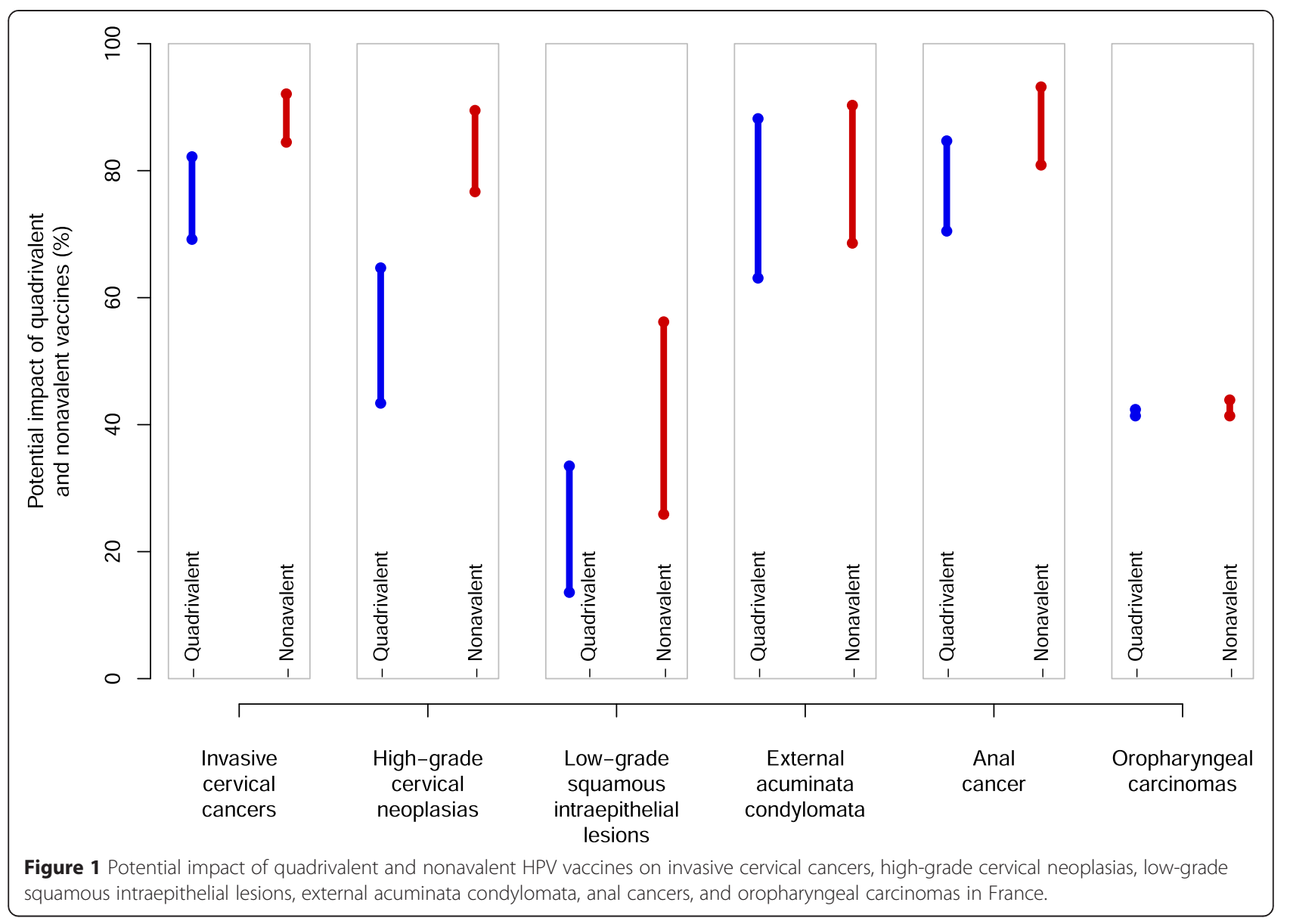

$76.7 \%$ (95\%CI 72.2 to 81.0 ) and $89.5 \%$ (95\%CI 86.4 to 92.3) for high-grade cervical neoplasias, and between $25.9 \%$ (95\%CI 17.5 to 35.0 ) and $56.2 \%$ (95\%CI 49.8 to 62.8) for low-grade squamous intraepithelial lesions.

The absolute additional impact of the nonavalent vaccine (i.e the number of additional cases that could be prevented by the nonavalent vaccine) as well as the relative additional impact (i.e compared to the quadrivalent vaccine) are presented in Table 2. Again, limited impact was found for the nonavalent vaccine compared to the quadrivalent one for external acuminata condylomata, anal cancer and oropharyngeal carcinomas. The absolute additional impact of the nonavalent vaccine lied between $9.9 \%$ and $15.3 \%$ for invasive cervical cancers, between $24.7 \%$ and $33.3 \%$ for highgrade cervical neoplasias, and between $12.3 \%$ and $22.7 \%$ for low-grade squamous intraepithelial lesions. The benefit of the nonavalent vaccine compared to the quadrivalent vaccine ranged between $12.0 \%$ and $22.1 \%$ for invasive cervical cancers, between $38.2 \%$ and $76.6 \%$ for high grade cervical neoplasias, and between $67.7 \%$ and $90.7 \%$ for low-grade squamous intraepithelial lesions.

\section{Discussion}

Based on large number of cases, the national multicentre EDiTH studies previously reported the HPV genotype distribution for different cervical, anal, or oropharyngeal diseases in France [14-20]. Assuming a 100\% vaccine efficacy and vaccination coverage, the EDiTH results suggested that a 6/11/16/18 quadrivalent HPV vaccine could prevent between $70 \%$ and $83 \%$ of ICC and anal cancer cases.

The attribution of cases to HPV types is often complicated by the existence of multiple infections characterized by the presence of several HPV types in the same tumor. Therefore, the potential benefit of an HPV vaccine is difficult to assess especially when HPV types not targeted by the vaccine are present. In all EDiTH studies and in the present study as well, we thus calculated a low and a high estimate of the vaccine impact based on presence of single or multiple infections. It is possible that the high estimate gives an overestimation of the potential impact of the vaccine since one assumes that HPV types targeted by the vaccine are causally related to the lesion in which they are found even in the presence of another HPV type. It is thus reasonable to believe that 
Table 2 Overall proportion (low and high estimates) of cases targeted by a quadrivalent or a nonavalent HPV vaccine

\begin{tabular}{|c|c|c|c|}
\hline & & Low estimate & High estimate \\
\hline \multirow[t]{4}{*}{ Invasive cervical cancers (EDITH I) } & Quadrivalent & $69.2[64.4-73.9]$ & $82.2[78.5-85.8]$ \\
\hline & Nonavalent & $84.5[81.0-87.8]$ & $92.1[89.5-94.3]$ \\
\hline & $\begin{array}{l}\text { Absolute additional Impact* } \\
\text { (\% of additional prevented cases) }\end{array}$ & $15.3 \%(p<0.001)$ & $9.9 \%(p<0.001)$ \\
\hline & Relative additional Impact** & $22.1 \%$ & $12.0 \%$ \\
\hline \multirow[t]{4}{*}{ High-grade cervical neoplasias (EDITH II) } & Quadrivalent & $43.4[36.9-50.0]$ & $64.7[59.6-69.9]$ \\
\hline & Nonavalent & $76.7[72.2-81.0]$ & $89.5[86.4-92.3]$ \\
\hline & $\begin{array}{l}\text { Absolute additional Impact } \\
\text { (\% of additional prevented cases) }\end{array}$ & $33.3 \%(p<0.001)$ & $24.7 \%(p<0.001)$ \\
\hline & Relative additional Impact & $76.6 \%$ & $38.2 \%$ \\
\hline \multirow[t]{4}{*}{ Low-grade squamous intraepithelial lesions (EDITH III) } & Quadrivalent & $13.6[5.6-24.1]$ & $33.5[25.6-41.4]$ \\
\hline & Nonavalent & $25.9[17.5-35.0]$ & $56.2[49.8-62.8]$ \\
\hline & $\begin{array}{l}\text { Absolute additional Impact } \\
\text { (\% of additional prevented cases) }\end{array}$ & $12.3 \%(p<0.001)$ & $22.7 \%(p<0.001)$ \\
\hline & Relative additional Impact & $90.7 \%$ & $67.7 \%$ \\
\hline \multirow[t]{4}{*}{ External acuminata condylomata (EDITH IV) } & Quadrivalent & $63.1[57.3-68.9]$ & $88.2[84.7-91.4]$ \\
\hline & Nonavalent & $68.6[63.1-73.8]$ & $90.3[87.2-93.2]$ \\
\hline & $\begin{array}{l}\text { Absolute additional Impact } \\
\text { (\% of additional prevented cases) }\end{array}$ & $5.4 \%(p=0.095)$ & $2.1 \%(p=0.318)$ \\
\hline & Relative additional Impact & $8.6 \%$ & $2.4 \%$ \\
\hline \multirow[t]{4}{*}{ Anal cancers (EDITH V) } & Quadrivalent & $70.5[64.7-76.0]$ & $84.7[80.6-88.7]$ \\
\hline & Nonavalent & $80.9[76.4-85.1]$ & $93.2[90.3-95.6]$ \\
\hline & $\begin{array}{l}\text { Absolute additional Impact } \\
\text { (\% of additional prevented cases) }\end{array}$ & $10.4 \%(p=0.001)$ & $8.5 \%(p<0.001)$ \\
\hline & Relative additional Impact & $14.7 \%$ & $10.0 \%$ \\
\hline \multirow[t]{4}{*}{ Oropharyngeal carcinomas (EDITH VI) } & Quadrivalent & $41.4[33.1-50.0]$ & $42.4[33.8-51.1]$ \\
\hline & Nonavalent & $41.4[33.1-50.0]$ & $43.9[35.5-52.2]$ \\
\hline & $\begin{array}{l}\text { Absolute additional Impact } \\
\text { (\% of additional prevented cases) }\end{array}$ & $0.0 \%(\mathrm{NC})$ & $1.6 \%(p=0.687)$ \\
\hline & Relative additional Impact & $0.0 \%$ & $3.8 \%$ \\
\hline
\end{tabular}

*Absolute additional potential impact of the nonavalent vaccine. **Relative additional potential impact of the nonavalent vaccine. NC, not calculated.

the "true" potential impact lies somewhere between the low and the high estimates.

If low estimate calculations are considered, the present study indicates that the absolute additional impact of a nonavalent vaccine is highest for CIN2/3 with a $33 \%$ increase in the proportion of cases targeted by the nonavalent vaccine. This additional benefit is intermediate for ICC (15\% increase), LSIL (12\%) and anal cancer (10\%) whereas almost no additional benefit is observed for genital warts (5\%) and oropharyngeal carcinomas (0\%). The EDiTH II study showed that between $43 \%$ and $65 \%$ of CIN2/3 cases were associated with HPV 6/11/16/18 (low and high estimates) [15] whereas the present study indicates that a nonavalent vaccine could target $77 \%$ and up to $90 \%$ of all CIN2/3 cases. This benefit on the prevention of CIN $2 / 3$ cases could have a real public health impact by reducing the costs related to the management of these lesions. It is indeed estimated that 25,000 to 30,000 conizations are performed in France annually [21]. The benefit on ICC would also be substantial with up to $92 \%$ of ICC cases that could be targeted by a nonavalent vaccine. Even if the proportion of LSIL cases attributed to HPV 6/11/16/18 was rather low (14-34\%), the proportion of cases associated with HPV types targeted by the nonavalent vaccine is increased by almost $90 \%$ ( $14 \%$ vs $26 \%$ considering the low estimates). However, for genital warts, only about $5 \%$ of cases are attributed to the additional HPV types found in the nonavalent vaccine (HPV 31/33/45/52/58) resulting in a low efficacy benefit. Similarly, no oropharyngeal carcinoma case was associated with these additional HPV types suggesting no additional benefit of a nonavalent 
vaccine in this group. This limited additional benefit on oropharyngeal carcinoma and genital warts is mainly explained by the fact that these conditions are almost exclusively associated with HPV types targeted by the bivalent or quadrivalent vaccines. Anal cancers are known to be mainly associated with HPV 16 . A possible explanation for the observed additional benefit of the nonavalent vaccine $(15 \%)$ is that we included some HIV positive patients (14\%) with higher risk of multiple infection ( $50 \%$ vs $20 \%$ in HIV negative patients).

It should be noticed that a strong epidemiological impact characterized by significant reductions in HPVrelated precancerous lesions and cancers may be achieved only if vaccination coverage reaches more than $80 \%$ [22]. However, by the end of 2013, the vaccination coverage with 3 doses reached only $20 \%$ of 16 year-old women in France [23]. By raising public awareness of the importance of HPV vaccination, general practitioners and gynecologists have to play an important role for increasing vaccination coverage.

A possible limitation of the present study is that HPV positivity in the EDiTH studies was based on HPV DNA detection only which could have resulted in a slight overestimation of the proportion of cancers potentially attributed to HPV. This is particularly true for oropharyngeal carcinomas for which HPV RNA detection would be a more accurate marker for those related to HPV infection. Moreover, other risk factors such as smoking or alcohol abuse are possibly involved. We calculated low and high estimates with the aim of taking into account the lack of knowledge regarding the causal relationship between each lesion and multiple HPV infection types. Low estimates suppose that the vaccine only prevents cases with genotypes targeted by the vaccine, while high estimates rather suppose that the vaccine prevents all cases where at least one genotype targeted by the vaccine is present, even in the presence of another genotype. This assumes that the other genotype is not involved in the occurrence of the lesion. Of course, true effects are in-between and it should be noted that alternative methods based on proportional (i.e., weighted) or hierarchical attributions of genotypes to disease categories have been proposed, providing intermediate estimates $[10,24,25]$. We nevertheless preferred to report estimates intervals rather that single estimates.

However, our results are in accordance with previous results reporting that a nonavalent vaccine would increase the protection from $70 \%$ to almost $90 \%$ of the infections responsible for ICC [13]. Moreover, a modelbased analysis showed that at the population level, the switch from a bivalent or a quadrivalent to a nonavalent vaccine would further reduce the occurrence of precancerous lesions and cervical cancer [26].
In France, both the bivalent and the quadrivalent vaccines are available with a predominant use of the quadrivalent [27]. Gardasil is currently indicated for the prevention of premalignant genital lesions (cervical, vulvar and vaginal), premalignant anal lesions, cervical cancers, anal cancers, and genital warts (condyloma acuminata) causally related to specific HPV types [28]. It should thus be borne in mind that the potential vaccine impact we assessed is hypothetical and concerns some outcomes (e.g. oropharyngeal carcinoma) for which no specific indication exists yet.

Pap smear screening is and will remain a very efficient tool for the prevention of ICC. Even if screening of elderly women should still be highly recommended, HPV vaccination could reduce and hinder the spread of the virus and prevent HPV-related diseases and cancers for which no screening strategies are available.

\section{Conclusion}

The nonavalent HPV vaccine showed significant increased potential impact compared to the HPV 6/11/16/ 18 quadrivalent vaccine for ICC, CIN2/3 and LSIL. Nonavalent vaccination could thus be a cost-effective alternative [29] with almost $90 \%$ of ICC, CIN2/3, genital warts and anal cancer cases being potentially prevented.

\section{Additional file}

Additional file 1: Table S1. Definition of low and high estimates.

\section{Abbreviations}

CIN: Cervical intraepithelial neoplasia; GW: Genital warts; HPV: Human papillomavirus; ICC: Invasive cervical cancer; LSIL: Low-grade squamous intraepithelial lesion.

\section{Competing interests}

FA received travel grants from SPMSD. XC and JLP received non-financial support from SPMSD. DR received personal fees from SPMSD and Ferring. JLSG received personal fees from SPMSD. PP performed medical writing services for SPMSD. ACJ and AD are employees of SPMSD.

\section{Authors' contributions}

DR, ACJ, JLSG, FA, XC, AD, JLP contributed substantially to the conception and design of the study. DR, JLSG, FA, XC, JLP contributed substantially to the acquisition of data. ACJ, AD, and PP analyzed the data. All authors contributed to the interpretation of data, drafting of the manuscript and to revising it critically for important intellectual content. All approved the final version to be published. All authors agreed to be accountable for all aspects of the work.

\section{Acknowledgements}

This study received financial support from Sanofi Pasteur MSD. The authors gratefully thank Nicolas Voirin and Pierre Pradat (www.alpha005.com) who performed medical writing services for Sanofi Pasteur MSD.

\section{Author details}

Service de gynécologie obstétrique, CHU Saint Jacques, Besançon, France. ${ }^{2}$ Sanofi Pasteur MSD, 12 rue Jonas Salk, 69367 Lyon, Cedex 07, France. ${ }^{3}$ Service d'Oto-rhino-laryngologie et chirurgie cervico-faciale, Hôpital Tenon, Université de Paris 6 et Faculté de Pierre et Marie Curie, Assistance 
Publique-Hôpitaux de Paris, Paris, France. ${ }^{4}$ Service de dermatologie, Centre Hospitalier Universitaire Saint-Jacques, Besançon, France. ${ }^{5}$ Department of Obstetrics and Gynaecology, Hôpital Nord, Assistance Publique des Hôpitaux de Marseille (APHM), Aix-Marseille Université (AMU), CNRS, IRD, Avignon Université, IMBE UMR 7263, 13397 Marseille, France. ${ }^{6}$ Department of Hepatology, Hôpital de la Croix-Rousse, Hospices Civils de Lyon, Lyon, France. ${ }^{7}$ Université Franche-Comte, F-25000 Besançon, France. ${ }^{8}$ EA 3181, FED4234, LabEx LipSTIC ANR-11-LABX-0021, CIC-BT 506, F-25000 Besancon, France. ${ }^{9}$ CHRU Besançon, F-25000 Besançon, France.

Received: 27 January 2015 Accepted: 22 April 2015

Published online: 02 May 2015

\section{References}

1. Dayyani F, Etzel CJ, Liu M, Ho CH, Lippman SM, Tsao AS. Meta-analysis of the impact of human papillomavirus (HPV) on cancer risk and overall survival in head and neck squamous cell carcinomas (HNSCC). Head Neck Oncol. 2010;2:15.

2. De Vuyst H, Clifford GM, Nascimento MC, Madeleine MM, Franceschi S. Prevalence and type distribution of human papillomavirus in carcinoma and intraepithelial neoplasia of the vulva, vagina and anus: a meta-analysis. Int J Cancer. 2009;124(7):1626-36.

3. Mehanna H, Jones TM, Gregoire V, Ang KK. Oropharyngeal carcinoma related to human papillomavirus. BMJ. 2010;340:C1439.

4. Miralles-Guri C, Bruni L, Cubilla AL, Castellsague X, Bosch FX, de Sanjose S. Human papillomavirus prevalence and type distribution in penile carcinoma. J Clin Pathol. 2009;62(10):870-8.

5. Bhatia N, Lynde C, Vender R, Bourcier M. Understanding genital warts: epidemiology, pathogenesis, and burden of disease of human papillomavirus. J Cutan Med Surg. 2013;17 Suppl 2:S47-54.

6. Villa LL, Costa RL, Petta CA, Andrade RP, Ault KA, Giuliano AR, et al. Prophylactic quadrivalent human papillomavirus (types 6, 11, 16, and 18) L1 virus-like particle vaccine in young women: a randomised double-blind placebo-controlled multicentre phase II efficacy trial. Lancet Oncol. 2005;6(5):271-8

7. Brown DR, Schroeder JM, Bryan JT, Stoler MH, Fife KH. Detection of multiple human papillomavirus types in Condylomata acuminata lesions from otherwise healthy and immunosuppressed patients. J Clin Microbiol. 1999:37(10):3316-22.

8. Potocnik M, Kocjan BJ, Seme K, Poljak M. Distribution of human papillomavirus (HPV) genotypes in genital warts from males in Slovenia. Acta Dermatovenerol Alp Panonica Adriat. 2007;16(3):91-6. 98.

9. 2013 vaccination schedule and recommendations from the "Haut Conseil de la santé publique" in France. BEH. 2013;14-15:129-158.

10. de Sanjose S, Quint WG, Alemany L, Geraets DT, Klaustermeier JE, Lloveras B, et al. Human papillomavirus genotype attribution in invasive cervical cancer: a retrospective cross-sectional worldwide study. Lancet Oncol. 2010;11(11):1048-56.

11. Li N, Franceschi S, Howell-Jones R, Snijders PJ, Clifford GM. Human papillomavirus type distribution in 30,848 invasive cervical cancers worldwide: Variation by geographical region, histological type and year of publication. Int J Cancer. 2011;128(4):927-35.

12. HPV vaccine works against nine viral types. Cancer Discov. 2014;4(1):OF2.

13. Serrano B, Alemany L, Tous S, Bruni L, Clifford GM, Weiss T, et al. Potential impact of a nine-valent vaccine in human papillomavirus related cervical disease. Infect Agent Cancer. 2012;7(1):38.

14. Pretet JL, Jacquard AC, Carcopino X, Charlot JF, Bouhour D, Kantelip B, et al. Human papillomavirus (HPV) genotype distribution in invasive cervical cancers in France: EDITH study. Int J Cancer. 2008;122(2):428-32.

15. Pretet $\mathrm{L}$, , Jacquard AC, Carcopino X, Monnier-Benoit S, Averous G, Soubeyrand $B$, et al. Human papillomavirus genotype distribution in high grade cervical lesions (CIN 2/3) in France: EDITH study. Int J Cancer. 2008;122(2):424-7.

16. Pretet $J$, Jacquard AC, Saunier M, Clavel C, Dachez R, Gondry J, et al. Human papillomavirus genotype distribution in low-grade squamous intraepithelial lesions in France and comparison with CIN2/3 and invasive cervical cancer: the EDiTH III study. Gynecol Oncol. 2008;110(2):179-84.

17. Aubin F, Pretet $J$, Jacquard AC, Saunier M, Carcopino $X$, Jaroud F, et al. Human papillomavirus genotype distribution in external acuminata condylomata: a Large French National Study (EDiTH IV). Clin Infect Dis. 2008;47(5):610-5
18. Abramowitz $L$, Jacquard $A C$, Jaroud F, Haesebaert J, Siproudhis L, Pradat $P$, et al. Human papillomavirus genotype distribution in anal cancer in France: the EDiTH V study. Int J Cancer. 2011;129(2):433-9.

19. Lacau St Guily J, Jacquard AC, Pretet JL, Haesebaert J, Beby-Defaux A, Clavel $C$, et al. Human papillomavirus genotype distribution in oropharynx and oral cavity cancer in France-The EDiTH VI study. J Clin Virol. 2011;51(2):100-4.

20. Haut conseil de la santé publique. Avis sur la modification éventuelle des recommandations vaccinales des jeunes femmes par le vaccin antipapillomavirus Gardasi ${ }^{\oplus}$. HCSP. Paris, 2008. www.hcsp.fr/hcspi/docspdf/ avisrapports/hcspa20080201_Gardasil.pdf (Visited on 04/12/2014).

21. Judlin P, Riethmuller D. Epidémiologie de l'infection due à HPV chez la femme après conisation. Lettre du gynécologue. 2011;362:22-4.

22. Riethmuller D, Pretet JL, Denis F, Aubin F, Pradat P, Clavel C, et al. Expected impact of a quadrivalent HPV vaccine in France. J Gynecol Obstet Biol Reprod. 2009;38(5):389-95.

23. Vaccination against Human Papillomavirus infections. Annual report 2014. Haut Conseil de la Santé Publique. http://www.hcsp.fr/Explore.cgi/ Telecharger?NomFichier=hcspr20140710_vachpvdonneesactualisees.pdf (Visited March 27, 2015).

24. Insinga RP, Liaw KL, Johnson LG, Madeleine MM. A systematic review of the prevalence and attribution of human papillomavirus types among cervical, vaginal, and vulvar precancers and cancers in the United States. Cancer Epidemiol Biomarkers Prev. 2008;17(7):1611-22.

25. Wentzensen N, Schiffman M, Dunn T, Zuna RE, Gold MA, Allen RA, et al. Multiple human papillomavirus genotype infections in cervical cancer progression in the study to understand cervical cancer early endpoints and determinants. Int J Cancer. 2009;125(9):2151-8.

26. Van de Velde N, Boily MC, Drolet M, Franco EL, Mayrand MH, Kliewer EV, et al. Population-level impact of the bivalent, quadrivalent, and nonavalent human papillomavirus vaccines: a model-based analysis. J Natl Cancer Inst. 2012;104(22):1712-23.

27. Les vaccins anti-papillomavirus humains (HPV). French Ministry of Health. http://www.sante.gouv.fr/questions-reponses-vaccin-anti-papillomavirushumain-gardasil-r.html (Visited April 2, 2015)

28. European Medicines Agency. Gardasil - Summary of Product Characteristics (Updated November 2013). http://www.ema.europa.eu/docs/en_GB/ document library/EPAR - Product_Information/human/000703/ WC500021142.pdf (Visited March 31, 2015)

29. Drolet M, Laprise JF, Boily MC, Franco EL, Brisson M. Potential cost-effectiveness of the nonavalent human papillomavirus (HPV) vaccine. Int J Cancer. 2014;134(9):2264-8

\section{Submit your next manuscript to BioMed Central and take full advantage of:}

- Convenient online submission

- Thorough peer review

- No space constraints or color figure charges

- Immediate publication on acceptance

- Inclusion in PubMed, CAS, Scopus and Google Scholar

- Research which is freely available for redistribution 